\title{
El trabajo docente y las relaciones con el estudiantado desde las representaciones de docentes en formación
}

Teaching work and relationships with students from the perspective of pre-service teachers' representations

\section{Volumen 17, Número 3 \\ Setiembre-Diciembre}

pp. 1-22

DOI: http://dx.doi.org/10.15517/aie.v17i3.29619

Gerardo Ignacio Sánchez Sánchez

Ximena Elizabeth Jara Amigo

Revista indizada en REDALYC, SCIELO

Revista distribuida en las bases de datos:

LATINDEX, DOAJ, REDIB, IRESIE, CLASE, DIALNET, SHERPA/ROMEO, QUALIS-CAPES, MIAR

Revista registrada en los directorios:

ULRICH'S, REDIE, RINACE, OEI, MAESTROTECA, PREAL, CLACSO 


\title{
El trabajo docente y las relaciones con el estudiantado desde las representaciones de docentes en formación
}

Teaching work and relationships with students from the perspective of pre-service teachers' representations

\section{Gerardo Ignacio Sánchez Sánchez ${ }^{1}$ Ximena Elizabeth Jara Amigo²}

\begin{abstract}
Resumen. El escenario actual de postmodernidad le plantea a la formación inicial de docentes el desafío de asegurar una adecuada inserción a contextos escolares altamente tensionados en sus demandas formativas. Esta investigación indaga, las representaciones que profesores en formación desarrollan del trabajo docente y las relaciones con el estudiante de educación primaria. Con un abordaje metodológico cualitativo, de alcance exploratorio - descriptivo, a partir del uso de entrevistas, el trabajo se configuró en una zona de diálogo con 50 estudiantes de pedagogía básica, de las menciones de lenguaje, matemática, ciencias naturales y ciencias sociales de la Universidad Católica del Maule. Los resultados muestran la representación del trabajo docente como una tarea humana dotada de una complejidad que se deriva del requerimiento de integralidad y de las demandas de una sociedad diversa y tecnológica. Se puede concluir que el proceso de incorporación al aula enfrenta a los docentes en formación a un territorio que hoy se define complejo e incierto. Debido a lo anterior es preciso asumir que los estudiantes son activos y heterogéneos, en sus disposiciones, intereses y capacidad de aprender $y$, en consecuencia, tensionan la relación y el status tradicional de autoridad docente. Desde el punto de vista de las implicancias para la formación inicial, este grupo de profesores en práctica no logra advertir que la misma racionalidad con la cual opera la institución escolar explica, en gran medida, la complejidad del nuevo territorio donde tendrá que llevar a cabo su trabajo.
\end{abstract}

Palabras clave: trabajo docente, relación profesor-estudiante, representaciones, postmodernidad, Chile

\begin{abstract}
The current situation of Postmodernity raises the challenge, to initial teacher training, to ensure a proper inclusion to school contexts which are highly stressed regarding training demands. This research explores the representations pre-service teachers have regarding teaching and their relationship with elementary school children. Using a qualitative methodological approach, with an exploratory-descriptive scope, starting from the use of interviews, the present piece of research was built in a dialogue arena with 50 students from the Elementary Teacher Education Program, with a minor in Spanish Language, Mathematics, Social and Natural Science of Universidad Católica del Maule. The results show the teaching work representation as a human effort equipped with a complexity derived from the requirement of integrality and otherness, and from the demands of a diverse, technological society. It can be concluded that while becoming integrated into the classroom, pre-service teachers are confronted with an area defined as complex and uncertain, in which it is important to consider that they are active and heterogeneous with respect to their willingness, interests, and capacity to learn, and as a consequence these factors stress the relationship and the teacher authority status. From the point of view of implications for initial teacher training, pre-service practitioners fail to see that the same rationality with which the school operates roughly explains the complexity of the new territory where they will have to carry out their work.
\end{abstract}

Key words: teaching work, teacher-student relationship, representations, postmodernity, Chile.

\footnotetext{
${ }^{1}$ Académico adscrito al Departamento de Formación Inicial Escolar de la Facultad de Educación, de la de Universidad Católica del Maule, Chile. Doctor en Ciencias de la Educación. Dirección electrónica:gsanchez@ucm.cl

2 Directora de la carrera de Pedagogía en Historia, Geografía y Ciencias Sociales de la Universidad Autónoma de Chile, Sede Talca, Chile. Magister en Curriculum y Evaluación. Dirección electrónica:xjaraa@uautonoma.cl
}

Artículo recibido: 31 de octubre, 2016

Enviado a corrección: 27 de marzo, 2017

Aprobado: 5 de junio, 2017 


\section{Antecedentes conceptuales y problemática de estudio ${ }^{3}$}

En la relación sujeto -contexto es posible constatar la existencia de una brecha importante entre la imagen ideal que los profesores se hacen de su función y los contextos de su quehacer. Esta cuestión se ve agravada por una sociedad que tiende a esperar más de lo que la escuela como organización de la modernidad es capaz de producir. Consecuentemente, se configuran condiciones complejas en las que tiene lugar la actuación docente.

Por una parte, se advierte a un profesorado afrontando importantes dificultades, fruto de la relación con grupos numerosos, lo cual produce una diversificación en el estudiantado en cuanto a conocimientos, capacidades e intereses, que difícilmente responde a una única propuesta formativa (Yániz y Villardón, 2006, p. 14), transformando la enseñanza en una tarea que puede resultar altamente gratificante, pero también constituir fuente de crisis y amenaza permanente, sea por las competencias que se requieren o por las condiciones materiales y simbólicas en que éstas son movilizadas (Tenti, 2007, p. 337).

Por otra parte, se visualizan cambios en las relaciones de poder entre las generaciones, acompañados de crisis de socialización y sentido, situaciones que afectan la tarea de los docentes como agentes sociales encargados de acompañar el crecimiento de la infancia y la adolescencia. Estos cambios condicionan las relaciones de poder y la convivencia, y tensionan los dispositivos de la institución escolar en lo referido a autoridad y orden.

Por último, la irrupción en el campo educativo, específicamente en los procesos de enseñanza y de aprendizaje de las nuevas tecnologías de la información y la comunicación, presiona el status del conocimiento sustentado tradicionalmente por el profesorado.

La consecuencia derivada de estos procesos sociales radica en que

Los valores que circulan en la escuela, la familia, y los medios de comunicación de masas no siempre son coincidentes o complementarios, sino que con frecuencia pueden ser contradictorios. El trabajo del maestro se inscribe en este nuevo cuadro de relaciones, lo cual le agrega una dosis creciente de complejidad. (Tedesco y Tenti, 2002, p. 9)

\footnotetext{
${ }^{3}$ Proyecto de investigación financiado por el Plan de Mejoramiento UCM1310 de Formación Inicial de Profesores
} 
Este nuevo escenario se configura en la tensión modernidad-postmodernidad, a la cual la institución educativa y sus actores no pueden escapar, y demanda la toma de una posición, expresada en adaptación pasiva o resistencia.

En el contexto de la modernidad:

Las escuelas públicas han dependido durante mucho tiempo de las tecnologías morales, políticas y sociales que legitiman una fe permanente en la tradición cartesiana de la racionalidad, el progreso y la historia. Conocemos muy bien las consecuencias. En los programas educativos el conocimiento y la autoridad no están organizados para eliminar las diferencias, sino para regularlas a través de divisiones del trabajo sociales y culturales. (Giroux, 1996, p. 7)

Sin embargo, en un escenario de postmodernidad, esta noción de escuela comienza a mostrar serias limitaciones para responder a las características, exigencias y requerimientos de la sociedad y sus actores.

Por tanto, según Giroux (1996) "los educadores bajo el contexto posmoderno se encuentran con un nuevo tipo de estudiante, forjado bajo principios organizativos delineados por la intersección de la imagen electrónica, la cultura popular y una terrible sensación de indeterminación" (p. 37).

En la práctica, "el profesorado constata la diversidad existente en las aulas, lo que le obliga a replantear finalidad, objetivos, metodologías" (Pérez, Martínez, Tey, Essombra y González, 2007, p. 48).

En consecuencia, ante el contexto de postmodernidad, es correcto señalar que la escuela y el profesorado se encuentran:

En una delicada encrucijada, viviendo una tensión inevitable y preocupante entre las exigencias de un contexto social móvil, cambiante, flexible e incierto, caracterizado por la complejidad tecnológica, la pluralidad cultural y la dependencia de los movimientos del libre mercado mundial por un lado y las rutinas, convenciones y costumbres estáticas y monolíticas de un sistema escolar inflexible, opaco y burocrático por otro. (Pérez, 2004, p. 163)

De acuerdo con los planteamientos de Hargreaves (1994):

Por una parte tenemos un mundo cada vez más postindustrial y posmoderno, caracterizado por el cambio acelerado, la comprensión intensa de tiempo y espacio, la diversidad cultural, la complejidad tecnológica, la inseguridad nacional y la 
incertidumbre científica. Opuesto a todo ello, sigue en pie un sistema de pensamiento modernista y monolítico que continúa persiguiendo propósitos profundamente anacrónicos partiendo de unas opacas e inflexibles estructuras. (p. 3)

De acuerdo con Biddle, Good y Goodson (2000), bajo las presiones de la posmodernidad:

Las certezas se están desmoronando; los discursos culturales que han sostenido a las reivindicaciones de la verdad se están deshaciendo, y el civismo, fundamento de la democracia, se está debilitando... los profesores se enfrentan a esta lluvia radioactiva, que se manifiesta por todas partes: un rol más amplio y cada vez más complejo y contradictorio; crecientes exigencias para cambiar y adaptarse a medida que se multiplican las innovaciones y el trabajo se vuelve más intenso e incierto. (p.125)

Frente a ello, una de las finalidades prioritarias de la escuela y el educador en el contexto de una sociedad y cultura postmoderna es entender la emergencia del sujeto transformado como el núcleo principal de la práctica educativa. Un sujeto que, desde la perspectiva de Tardif (2004), "se manifiesta, genera resistencias y del cual es preciso obtener el empeño considerando sus motivos, es decir, sus deseos y los significados que atribuyen a su propia actividad de aprendizaje" (p. 96).

Se deriva de lo anterior que, el trabajo docente en la escuela, no puede concebirse ya como un proceso lineal de transmisión de conocimientos científico-culturales generados en la vida intelectual y material de la sociedad, y que se organizan y simplifican en módulos académicos para su aprendizaje secuencial. Las complejas redes sociales de intercambio de información y su imparable influencia en la vida cotidiana plantean a la escuela y a sus profesores retos diferentes. Se enfrentan a un estudiante distinto con nuevas demandas e intereses, que imponen al trabajo de los profesores una clara carga emocional. Cuando les enseñan a sus estudiantes tienen que utilizar y dirigir sus propias emociones y las de ellos. De este modo, crean unas relaciones emocionales con sus estudiantes (Liston y Zeichner, 1997, p. 119).

Este contexto de postmodernidad afecta la función asignada a la escuela y, por añadidura, el lugar que ocupaba el docente como un simple dispensador de conocimientos, con ello se difumina la permanencia de los viejos modelos pedagógicos (Edwards y Pintus, 2001, p. 57) y se plantea el desafío de reexaminar la naturaleza del trabajo docente. En su 
cotidianidad, el trabajo docente es "un conjunto de interacciones personalizadas con el cuerpo estudiantil para conseguir su participación en su propio proceso de formación y atender a sus distintas necesidades" (Tardif, 2004, p. 87).

En relación con lo anterior, es posible observar la tensión que enfrentan los sistemas educativos actuales por cuanto:

[...] están basados en un modelo de educación homogénea, cuando hoy la sociedad globalizada se caracteriza cada vez más por su diversidad. Trabajar con la diversidad como un aspecto positivo es un desafío que nuestros sistemas educativos manejan con dificultad. De hecho, ésta es vista más bien como una traba, cuando, por el contrario, debe ser considerada una fortaleza. Los sistemas privilegian esquemas de trabajo homogéneos, con calendarios y ritmos de progreso uniformes, o bien seleccionan a los estudiantes según características que permitan contar con grupos "similares", ya sea en términos de estatus social, habilidades, u otros criterios. Todo esto facilita la administración burocrática, pero nos distancia de la realidad del mundo actual cada vez más diverso; reproduce la inequidad social y quita a la diversidad la posibilidad de contribuir al aprendizaje. (Machado, 2015, p. 1)

El proceso se dificulta aún más debido a que el profesor ya no es el único poseedor de todo el conocimiento y el alumno no es el agente pasivo del proceso de enseñanzaaprendizaje. El estudiante actual es inquieto, informado, creativo, con intereses e inquietudes propias, dispuesto y capacitado para enfrentar, apoyar y cooperar no solo en su propio proceso de enseñanza-aprendizaje, sino también en el de los demás. Frente al joven postmoderno que se define como un sujeto interactivo, espontáneo, inquieto, habilidoso en el uso de las tecnologías (Alfaro, 2011, p. 8), el profesorado se enfrenta a nuevas demandas y al despliegue de otro tipo de respuestas y actuaciones.

Situados en el espacio de la formación inicial de profesores, surge el desafío a la preparación de profesores para atender a los nuevos estudiantes y hacer frente a las nuevas formas de aprendizaje-enseñanza, con lo cual se asegura su temprana y adecuada inserción en contextos escolares altamente tensionados por el cambio en los actores y por la capacidad de respuesta de la institución escolar hacia ellos. Lo anterior exige repensar la racionalidad con la cual se ha concebido la formación de docentes.

La evidencia muestra que la formación del profesorado ha girado en torno a un modelo de aplicación del conocimiento: los alumnos asisten a clases basadas en disciplinas constituidas por conocimientos teóricos parcializados. Luego, realizan sus prácticas para 
"transferir" esos conocimientos, y una vez concluida su formación comienzan a trabajar solos, aprendiendo el oficio en la práctica y, en la mayoría de los casos, logran constatar que los conocimientos teóricos no se aplican con facilidad a la realidad cotidiana dentro de la sala de clases (Day, 2006; Schön, 1987, 1998, 2010).

Dado los requerimientos que, desde la postmodernidad, tensionan el territorio de lo educativo, surge la necesidad de indagar en la comprensión que el cuerpo docente en formación desarrolla de su trabajo, específicamente en las representaciones respecto a los actores (docente y estudiantes) y a la naturaleza y características de la tarea educativa.

Las preguntas de investigación que fundamentan el estudio son:

1. ¿Cuáles son las características que enfrenta en la actualidad el trabajo docente?

2. ¿Qué características presenta la relación e interacción profesor - estudiante?

Con base en estas preguntas de investigación, el objetivo que persigue este estudio es conocer la representación del profesorado en formación en relación con el trabajo docente en términos de sus características y aspectos condicionantes. Desde la perspectiva del profesorado en formación se busca profundizar en las relaciones de encuentro y desencuentro entre el profesor y sus estudiantes.

\section{Diseño y metodología}

El problema de esta investigación se configuró en una zona de diálogo entre 50 estudiantes de pedagogía básica con mención de la Facultad de Ciencias de la Educación de la Universidad Católica del Maule, quienes a través de sus representaciones ofrecieron aportes conceptuales desde los cuales construimos nuestro objeto de investigación.

Mediante una metodología cualitativa, de alcance exploratorio-descriptivo, el trabajo recupera algunos insumos del paradigma de la narrativa en las ciencias sociales, por cuanto nos interesa principalmente analizar las representaciones que los propios profesores en formación atribuyen, en sus relatos orales, a los actores del aula (profesor - estudiantes) y la naturaleza del trabajo docente.

Cabe destacar la centralidad de las entrevistas a la comunidad docente en formación. En este caso fue utilizada la técnica de la entrevista semiestructurada con aportes de los relatos de vida (Berteaux, 2005). Este tipo de entrevista facilita la comparación entre respuestas y permite establecer recurrencias y diferencias discursivas en torno a los conflictos por relevar.

El tipo de indagación realizada es retrospectiva y no longitudinal. Es decir, no seguimos una cohorte en el tiempo con la finalidad de observar sus trayectorias, sino que partimos de 
un presente determinado (el año 2016) y desde ahí orientamos las entrevistas hacia la recuperación de experiencias pasadas.

El trabajo de campo se llevó a cabo en dos instancias. En un primer momento, se centró en entrevistas a estudiantes de la Facultad de Ciencias de la Educación de nuestra Universidad. Esta primera indagación —compuesta de 10 entrevistas - aportó datos para realizar los primeros ajustes teóricos, y confrontar así el marco conceptual indagado con las categorías de los entrevistados. En un segundo momento, mediante la consideración de criterios de saturación teórica (Glaser y Strauss, 1967), se realizaron 50 entrevistas a estudiantes de pedagogía básica de las menciones de lenguaje, matemática, ciencias naturales y ciencias sociales: 35 mujeres y 15 varones, cuyas edades oscilan entre los 23 y 30 años. Con algunas de las personas entrevistadas se efectúo un segundo encuentro, con fines de aclarar, ampliar y/o profundizar ciertos contenidos surgidos la primera vez.

Quienes realizaron la entrevista se seleccionaron considerando, en primer lugar, que se encontraran transitando la etapa final de sus carreras, específicamente, su proceso de práctica profesional. Se priorizó, asimismo, el abarcar diferentes perfiles de estudiantes, integrando jóvenes de distintas menciones y en diferentes contextos de inserción: urbano y rural. De este modo, para efectos de esta comunicación se pudo acceder a relatos que expresan experiencias de socialización y de formación del grupo en su conjunto.

El procedimiento de análisis implicó la contextualización y organización significativa de las entrevistas, según frases significativas; identificación de temas y subtemas (elaboración de índice temático); escritura y redacción del análisis por tema. A cada entrevista se les asignó un código para facilitar su manejo durante la posterior etapa de análisis (PF con número consecutivo).

\section{Resultados}

\subsection{Representaciones sobre los profesores y su labor}

Tal como señala la Organización de las Naciones Unidas para la Educación, la Ciencias y la Cultura (2008), en el Informe Delors, la educación se ve obligada a "proporcionar las cartas náuticas de un mundo complejo y en perpetua agitación y, al mismo tiempo, la brújula para poder navegar en él” (p. 95). En ese contexto, el trabajo del profesor en la escuela, entendida en un sentido amplio, debe alejarse de la visión tradicional vinculada a la transmisión lineal de conocimiento científico-cultural, y ser capaz de responder 
a las incertidumbres de los nuevos tiempos, consciente de que no resulta fácil intentar enseñar cuando no se entiende mucho qué pasa, pues las certezas tienden a flaquear.

El cuerpo docente en formación, al ser consultados por la labor de docencia, alude a una representación del trabajo docente, construida en torno a las siguientes dimensiones:

\subsubsection{Trabajo docente. Naturaleza}

En primer lugar, el cuerpo docente en formación representan el trabajo docente como tarea humana, demandada fuertemente por el requerimiento de integralidad y alteridad, en lo referido a la escuela como institución de educación primaria, y al docente, como actor clave.

El trabajo docente desarrollado en las escuelas está interpelado a la entrega de educación integral. Este código se refiere a la necesidad percibida por los y las docentes en formación acerca de que la educación de hoy debe ser no solo en el ámbito académico, vale decir, referido estrictamente a los conocimientos declarados en los planes del estudio, sino también en valores, actitudes y principios de actuación, con el fin de formar personas que aporten al desarrollo de la sociedad. Este código queda reflejado en las siguientes citas:

[...] La escuela debería cumplir un rol fundamental en cuanto a la posmodernidad, ayudando a los niños a formar un pensamiento crítico y una mirada amplia del mundo, con esto me refiero a que puedan ser capaces de reflexionar y de entregar opiniones respecto a algún tema de contingencia en diferentes ámbitos, como lo son: la política, la religión, la literatura, entre otros. Sin embargo, creo que la escuela solo en algunos aspectos cumple a cabalidad esta misión y en otros lamentablemente está en deuda, debido a que se da prioridad a algunas saberes y otros no, dejando de lado la formación integral del niño y que al final se tiende a dirigir por el lado práctico y el que se pide o exige con mayor preocupación que son los contenidos que posteriormente serán evaluados. (PF4)

[...] La escuela debería volver a tomar el rol fundamental en la formación integral de las personas, educándolas en valores e inculcándoles conocimientos que les servirán en la vida cotidiana. Solo así lograremos una educación de calidad e integral, abarcando todas las áreas del saber. Otorgando elementos que les serán claves en la adultez. (PF10) 
En el caso del profesorado, también su gestión aparece asociada a la idea de labor integral, con una imagen de la tarea del y la docente que implica no solo impartir ciertas materias para lograr determinados aprendizajes, sino que su quehacer lo lleva naturalmente a involucrarse también con el estudiantado en importantes procesos a nivel motivacional, emocional, social y familiar. Algunas de sus referencias son:

[...] Enseñar no es una tarea fácil, implica una máxima entrega por parte del docente, que no solo se fundamenta en traspasar contenidos (elemento que también es importante) sino que además, se basa en buscar la mejor manera o metodología para lograr que sus estudiantes se motiven, entiendan y logren desarrollar diferentes habilidades. Sin olvidar también que deben saber mediar con problemas emocionales y/o familiares para que éstos no afecten el crecimiento cognitivo del estudiante. (PF5)

\subsubsection{Trabajo docente. Complejidad}

Entre el cuerpo docente en formación, emerge una toma de conciencia respecto de la complejidad que encierra la labor del profesorado dado por la demanda de integralidad que lleva adosada el trabajo, las capacidades docentes que supone movilizar y por las condiciones de operación, se constata así un cambio de percepción en ellos, desde una visión simplista de la labor docente, donde solo se pensaba que se dedicaba a realizar la clase hasta que, gracias a sus experiencias de práctica, descubren la profundidad del trabajo dentro y fuera de aula, en lo que implica la preparación, el desarrollo y evaluación de las tareas, con la correspondiente inversión de tiempos, capacidades y energía. Sus referencias aluden a:

[...] Hoy en día comprendo que el tiempo designado es ínfimo comparado con todo lo que comprende el quehacer pedagógico: conocer a sus estudiantes, comprender sus necesidades, determinar objetivos de aprendizaje y su metodología de enseñanza, disponer los recursos a utilizar y crear los instrumentos de evaluación. (PF2)

[...] Ellos hacen mucho más de lo que pude haber llegado a imaginar. Nunca se me pasó por la cabeza que el profesor debía planificar clase a clase lo que iba a enseñar, cómo lo iba a enseñar y el para qué lo iba a enseñar; y por otra lo difícil que es lograr la respuesta y motivación de los estudiantes. Tampoco uno se imagina la carga horaria que tienen, la cantidad de contenidos que deben manejar en su totalidad, para que al momento que un alumno pregunte, puedas tener la respuesta. (PF22) 
Estos relatos ponen de manifiesto una clara conciencia de las "demandas de trabajo" que caracterizan la docencia con tareas que exceden el espacio aúlico, referidas a la preparación de clases, atención de padres y madres, trabajo de planificación y evaluación. Una cita indica:

[...] Los profesores corren de un lado a otro, queriendo sentarse para tomar un café pero sin poder porque recuerdan que deben hacer una u otra cosa, desde atención a apoderados o viendo a algún niño que se cayó o que está llorando por algún motivo, recibiendo apoderados que van a reclamar porque sus hijos se han sacado una mala nota porque la profesora "le tiene mala". Y luego, cuando ya han logrado sentarse en una hora administrativa, enloquecen contra el tiempo para poder revisar las pruebas de un curso completas porque los niños insisten todo el día para que les entregue una prueba de un día para otro. (PF12)

\subsubsection{Trabajo docente. Factores condicionantes}

Es importante constatar la presencia de ciertos factores condicionantes de la complejidad reconocida en el ejercicio docente.

Por una parte, el aumento en la diversidad, referido a la idea de que el o la docente de hoy debe desempeñarse en un entorno más diverso derivado de la personalidad, formas de aprender, valores y principios que muestra el estudiantado. Algunas de las referencias lo grafican:

[...] Personalmente el desafío más grande que estoy viviendo en la práctica es intentar conocer las personalidades de todos los estudiantes y lo difícil que resulta dar respuesta a sus necesidades que también son diversas. (PF15)

[...] Porque cuando uno está en el aula enseñando se enfrenta a la complejidad insospechada de la diversidad de estudiantes en sus actitudes, motivaciones e intereses, desde aquellos a los cuales les agrada lo que se está enseñando hasta aquellos que lo consideran aburrido. (PF44)

Desde la formación inicial, es importante constatar que el área de la infancia y la juventud, como objeto de estudio, es tematizado a lo largo de la formación, pero se trataría de una clase de temas que se activan y requieren ser vueltos a revisitar ante situaciones 
puntuales del aula, y que se tornan muy recurrentes en las primeras experiencias prácticas como bien lo reconoce la comunidad docente en formación.

Por otra parte, se constata un mayor acceso a tecnología, lo cual supone oportunidades para el trabajo docente, pero también desafíos en cuanto a cómo elegirlos e incorporarlos efectivamente en su trabajo, lo que obliga a superar en muchos casos los propios sesgos instalados respecto a ellos.

[...] Resulta complejo lidiar con tanta tecnologías, los niños parecen controlados por la imagen y el teclado, sólo eso les importa y motiva, en clase todo lo encuentran aburrido. (PF14)

Al escenario ya descrito se suma la centralidad que adquiere el Sistema de Medición de la Calidad de la Educación (SIMCE), lo que hace más complejas las condiciones de operación en que se desarrolla el trabajo docente. Ello se traduce en la existencia de un profesorado que se ve obligado a centrar su quehacer en mejorar los estándares de calidad de los establecimientos, con lógicas de actuación que no necesariamente se mantienen en sintonía con el discurso de la formación integral, o la centralidad declarada en el estudiante y sus necesidades.

[...] A diferencia de lo que se vive hoy, debido a que en muchos colegios se trabaja con base al SIMCE, lo que implica horas extraordinarias tanto de los alumnos como de los docentes, siendo capaces de dejar sin deporte y otras asignaturas que no mide el SIMCE, como obligarlos a asistir los días sábados para reforzar las debilidades, y así mejorar los resultados, dejando de lado la educación integral. (PF49)

\subsubsection{Trabajo docente. Valoración social}

A estos factores condicionantes, los profesores en formación agregan la paradoja que se produce entre un discurso que por un lado, alude a la importancia de la educación para la sociedad de la cual ellos son progresivamente conscientes; y por otro, la existencia de una crítica permanente al quehacer de los docentes y el reconocimiento social que tiene la profesión.

Por una parte, emerge la importancia para la sociedad, referida a la percepción de que la labor docente es relevante para el desarrollo de la sociedad, dado que el fin último de esta es formar personas para el mejoramiento social. Algunas referencias lo muestran con claridad: 
[...] La tarea del profesor es formar seres integrales, los cuales serán los ciudadanos del país del mañana, serán los líderes y los responsables de la sociedad, de ahí la relevancia de los profesores. (PF3)

Por otra parte, nos encontramos con una importancia mal valorada, o derechamente un "aumento de la desvaloración", con relatos de una profesión que ha sufrido una devaluación cada vez mayor con el correr del tiempo. En sus referencias indican:

[...] Ahora lo veo, como un luchador en sí mismo porque con el tiempo me he dado cuenta de que su labor no es para nada fácil, ya que es un desafío que requiere de constante perfeccionamiento, innovación y entrega, sobre todo entrega y que tiene que luchar contra ese camino bifurcado por malos sueldos, falta de tiempo, estigmas sociales. (PF32)

[...] Más desgastados y aburridos con la profesión, ya que ésta, se encuentra demasiado desvalorizada, ya sea por los mismos docentes quienes no presentan el mismo interés por enseñar, que los docentes de hace 20 años atrás; o también porque las condiciones laborales y económicas por parte del Estado y el sistema no satisfacen la demanda de los docentes, quienes cada vez encuentran que su profesión no es valorizada por la sociedad. (PF6)

La representación que docentes en formación hacen del trabajo docente $-\mathrm{y}$ con un fuerte y explícito sentimiento de añoranza a lo que pensaban o a su experiencia escolar pasada como estudiantes de educación básica - indica una clara conciencia respecto a un trabajo que se va tornando más difícil que en los orígenes de los sistemas educativos cuando los principios y valores fundamentales del programa escolar moderno no se cuestionaban y otorgaban legitimidad, protección y seguridad a la tarea de la comunidad docente. Cuando se ven enfrentados a los contextos de aula - producto de sus procesos de práctica - constatan con claridad que la infancia se transforma en un tema tan desconcertante y, por eso mismo, ineludible de ser repensado y resuelto, si se pretende cierto éxito en la tarea docente. 


\subsection{Los actores del aula: Cuerpo docente y cuerpo estudiantil ¿encuentro o desencuentro?}

El ejercicio de la docencia no se encuentra exento de cierta pérdida de legitimidad y autoridad, pues se desarrolla en una contexto cada vez menos regulado desde pautas claras. Desde un ángulo, las familias suelen demandar en forma excesiva a las escuelas en búsqueda de límites y contención, con respuestas que generan más bien confusión y escaso avance.

Desde otro ángulo, la relación con el estudiantado se torna un desafío resbaladizo, haciendo necesario asumir que los alumnos son activos y heterogéneos, en cuando a sus probabilidades de acción, su capacidad de aprender, y sus disposiciones. En consecuencia, la acción principal del profesorado consiste en hacer que las acciones de los alumnos se armonicen con las suyas, en vez de resistirse a ellas.

\subsubsection{El profesor y sus mecanismos de interacción: La coacción y la autoridad}

En el caso del profesorado en formación, los relatos aluden a una pérdida de autoridad, respeto y prestigio, la cual se sustenta en la percepción de que antes los y las docentes contaban con un mayor respeto y valoración por parte de quienes estudian y entorno en general, lo cual se traducía en sentimientos de admiración e incluso miedo por parte de estos, situación que contrasta con las relaciones más horizontales que en la actualidad caracteriza a los estudiantes, lo que genera para el profesorado una clara dificultad al momento de poder controlar la conducta de los estudiantes. Este código queda reflejado en las siguientes expresiones:

[...] Existe un notorio cambio en los niños del siglo XXI. Antiguamente existía mayor respeto por la gente adulta, situándonos en una sala de clases, existía total obediencia y admiración por el docente, incluso temor. (PF47)

[...] Además en algunos casos por lo que he podido observar durante mi experiencia de práctica, se está perdiendo el respeto o la imagen de autoridad que tenían los profesores frente a los estudiantes y apoderados. (PF12)

Estos relatos dan cuenta de la tensión que experimenta la pedagogía tradicional, ya que se trata de una pedagogía de modelos unilaterales, cerrados y prescritos, que en la actualidad tienen serias dificultades para ser sostenidos por su incapacidad para sintonizar con la vida real y necesidades de infantes y jóvenes. 
Seamos conscientes de que estos modelos refieren a una escuela que tradicionalmente no había sido pensada para satisfacer los intereses de la infancia, situación que emerge en el relato de la comunidad docente en formación, y que se refleja fuertemente en un pasado pedagógico caracterizado por la limitada participación de los niños y las niñas de antes, percepción según la cual los y las estudiantes de antaño afrontaban su proceso de enseñanza de manera más pasiva, acatando lo que el profesor y sus padres decían sin mayor cuestionamiento, pues la coacción se constituía en la principal tecnología de interacción utilizada por el profesorado. Este código muestra las siguientes referencias:

[...] Antes uno era más sumiso, no cuestionaba la palabra del profesor, existía un respeto absoluto, y no se le alzaba la voz ni se les contestaba ante una llamada de atención, en cambio ahora son todo lo contrario, siempre están cuestionando todo. (PF29)

[...] Similar situación ocurría en los hogares, donde prevalecían generalmente estilos de familias más bien estrictas, con bastantes normas que limitaban la participación de los niños dentro de las decisiones familiares. (PF1)

\subsubsection{El estudiante postmoderno y sus exigencias de persuasión}

En el escenario actual, el cuerpo estudiantil se muestra más interactivo, espontáneo, inquieto, resuelto y hábil en el uso de tecnologías, y por tanto dispuesto a ofrecer resistencia a las propuestas educativas en las que participa.

En un esfuerzo por dar cuenta de su perfil, los relatos lo capturan en las siguientes representaciones:

Niñez de hoy más inquieta y participantes: código referido a la representación según la cual, los niños y las niñas de hoy son más inquietos cognitivamente, responden mejor ante metodologías más participativas y prácticas donde ellos y ellas puedan intervenir activamente en sus aprendizajes y en el desarrollo de las clases. Por esta misma razón, cuestionan y exigen a sus docentes. Algunos relatos lo evidencian:

[...] En la actualidad los estudiantes están más despierto, cuentan desde pequeños con herramientas tecnológicos, que les generan de manera fácil un mayor acceso a una variedad de información, por lo que posee más conocimientos, exigiendo a la misma vez más a sus profesores por el alto nivel de inquietudes que poseen. (PF20) 
[...] Desde el punto de vista cognitivo, siento que los estudiantes están más inquietos intelectualmente. (PF7)

[...] Ya no es suficiente con entregarles y entregarles saberes, pues los alumnos necesitan experimentar con los conocimientos, razón que hace que el aprender haciendo sea una de las bases fundamentales del aprendizaje de hoy. (PF13)

[...] Los estudiantes de hoy son más cuestionadores, les gusta preguntar todo, hacer suposiciones respecto a distintos temas, y sobre todo exigentes. (PF9)

Niñez de hoy más desafiante y con problemas de comportamiento: Este código se refiere a que la niñez de hoy se muestra más violenta con sus pares, docentes y entorno en general. Dicha situación se observa con mucha mayor frecuencia que antes, expresada en problemas de convivencia entre pares, faltas de respeto hacia el cuerpo docente, además de problemas de comportamiento en clases y asimilación de normas. Los siguientes relatos lo manifiestan:

[...] Los niños de hoy se han convertido en niños contestadores con los profesores, respondiéndole de manera desafiante. (PF24)

[...] En cuanto a lo actitudinal también existen variaciones, ya que anteriormente los estudiantes eran más tranquilos y más respetuosos, en cambio ahora son hiperactivos y más rebeldes en el sentido no respetar reglas. (PF16)

[...] En algunos establecimientos que he asistido en mis prácticas educativas el bulling está a la orden del día y es un problema bastante serio. (PF26)

Niñez de hoy más empoderada de la tecnología y del acceso a la información: Código referido a la imagen de que la comunidad estudiantil de hoy tiene mucho mayor acceso a la tecnología de la informática y con ello a la información, lo cual supone un desafío para el grupo docente a la hora de desarrollar estrategias pedagógicas en el espacio del aula. Este código se manifiesta en las siguientes representaciones:

[...] En la actualidad los estudiantes cuentan desde pequeños con herramientas tecnológicos, que les generan de manera fácil un mayor acceso a una variedad de 
información, por lo que posee más conocimientos, exigiendo a la misma vez más a sus profesores por el alto nivel de inquietudes que poseen. (PF35)

[...] Hay cambios y considerables, pues estamos en un tiempo que podríamos llamarlo o definirlo como "tecnológico", donde los alumnos han tomado este recurso a veces para bien y otras para mal. (PF19)

Niñez de hoy menos motivada por el aprendizaje que ofrece la escuela: referido a la imagen según la cual el cuerpo estudiantil no está motivado naturalmente por la escuela y por el proyecto de aprendizaje que esta le ofrece, el cual es visto como un deber a cumplir e incluso como un lugar donde se pierde la libertad. Al parecer los intereses del estudiantado están puestos en asuntos como sus relaciones sociales, entretención e incluso en asuntos que son propios de personas adultas. Este código tuvo 11 referencias, algunos ejemplos son:

[...] Los niños y las niñas no se responsabilizan de sus deberes, pues no ven el objeto de ir al colegio, para ellos no es un espacio liberador, ni motivante, sino un deber, una cárcel de sus deseos, pues no pueden expresarse como lo esperan. Esta misma pérdida de compromiso con su proceso educativo hace que los niños se comporten de una forma disruptiva, pues no tienen una motivación intrínseca que les permita atender gustosamente las actividades preparadas por el docente. (PF36)

[...] Es cada vez más frecuente y evidente el desinterés por parte de los estudiantes hacia la escuela y todo lo que involucre esta ya que podría decir que en todos los cursos en los cuales he estado ya sea observando o realizando clases, la mayor preocupación de ellos son el celular, juegos, computador, videos de internet y lo que más me sorprende los novios o novias. (PF17)

\subsubsection{Factores explicativos del perfil de estudiante}

En ese perfil de estudiante que hoy habita las aulas, el cuerpo docente en formación identifica dos factores explicativos: el influjo que ejercen las tecnologías y el papel formativo de la familia. Sin embargo, no logran advertir el influjo que la misma escuela -como institución de la modernidad- tiene en la configuración de este nuevo escenario.

Respecto al primer factor, advierten la tecnología como un elemento perjudicial: código referido a que el profesorado ve el uso de tecnologías de la información como un elemento 
nocivo para el proceso de enseñanza y de aprendizaje, ya que constituye un distractor para el cuerpo estudiantil y para avanzar en la entrega ordenada del contenido y el desarrollo planificado de la clase. Este código queda reflejado en los siguientes relatos:

[...] El uso de las tecnologías y nuevas metodologías bombardean a los estudiantes desde diversos ámbitos, y eso favorece el que los estudiantes tengan momentos donde pierdan su concentración, o "desarrollen de mala manera” trabajos grupales. (PF27)

[...] En conclusión creo que el cambio es evidente más aún si le sumamos que el acceso a la tecnología, lo poseen desde muy pequeños, y lamentablemente en ocasiones en vez de ser un aporte en el aula, representa una distracción para los estudiantes. (PF34)

En relación con los padres y madres de hoy, se les considera ausentes y menos autoeficaces. Este código refiere a la imagen según la cual, los padres y las madres de hoy se sienten menos capaces de llevar la crianza de los niños y las niñas, y por ello están más alejados de los procesos de enseñanza de sus hijos e hijas en la escuela, incluso, en algunos casos, delegan y traspasan la responsabilidad de parte de la formación, al cuerpo docente. Este código se manifiesta en los siguientes relatos:

[...] Otro punto importante es la manera acelerada en la que se crían los niños y niñas, en algunos casos por las necesidades que tiene sus padres que en muchos casos privilegian sus responsabilidades individuales por sobre la dedicación sobre todo afectiva que necesitan estos niños. (PF45)

"[...] Los padres están menos involucrados con el desarrollo educativo de sus hijos, por lo que en cierta medida, descuidan la educación y prefieren que los "profesores" o bien el colegio cumpla la misión de educarlos, de entregarles valores, etc. (PF31)

\section{Discusión de resultados}

El profesorado en formación afronta la práctica con ciertos proyectores conceptuales, imágenes preformativas y sesgos, que le permiten disponer de una representación parcial de la realidad, con una visión situacional reducida caracterizada por indicadores de comprensión limitada, pues sus puntos de referencia para navegar en el territorio del aula son aún insuficientes y suelen verse agravados cuando súbitamente, enfrentado al trabajo en aula, constata que nada o muy poco se comporta como estaba previsto, y se ve necesitado 
de reglas flexibles y cambiantes. En ese sentido, la explicación teórica de carácter omnisciente presentada en la universidad no le sirve, o no le brinda todas las respuestas que requiere. De acuerdo con Carbonneau y Hétu (2010, p. 128), "Una formación profesional que gire, en un principio, en torno a la comprensión y al análisis teórico de la intervención contribuye a retrasar la aprehensión de la economía pedagógica".

El proceso de inserción al aula enfrenta al cuerpo docente a un territorio que hoy se define por su complejidad e incertidumbre, condicionando el perfil de sus actores (docente estudiantes) y la naturaleza de la tarea, sin aun reparar que la misma racionalidad con la cual opera la institución escolar, explica en gran medida las características de este nuevo territorio.

En relación con el perfil de los actores del aula y las relaciones que se producen entre profesores y alumnos, el profesorado en formación constata que sus visiones normativas no se corresponden con el perfil de un estudiantado que se muestra más interactivo, inquieto, resuelto, cuestionador y desafiante, consciente que es sujeto de derechos y por tanto, dispuesto a ofrecer resistencia a las propuestas educativas que la escuela y el profesorado le ofrecen en términos de posibilidades de aprendizaje. Logran con claridad y certeza configurar un perfil del y la estudiante que habita el espacio del aula, a partir de dos elementos sustanciales: la tecnología y la diversidad, las cuales tensionan el desarrollo de la docencia.

A partir de estos dos elementos, son conscientes que el status tradicional de la autoridad docente tambalea y obliga a buscar otras formas de interacción pedagógica, sin embargo, no logran escapar a sus propios sesgos, que los tienden a anclar en la añoranza de la figura tradicional docente, donde el respeto y la autoridad se mezclan con la admiración y el miedo, elementos fundantes de la pedagogía de la modernidad. Muestran tensiones no resueltas respecto al uso de los aparatos celulares, por tanto, si bien reconocen la irrupción de las tecnologías de la información en el aula, evidencian dificultades para convertirla en un aliado del proceso educativo desde el cual construir una relación pedagógica distinta con el estudiantado postmoderno. Asimismo, advierten la diversidad presente en el aula y la operacionalizan en la variedad de estilos y disposiciones hacia el aprendizaje, no obstante, no logran generar un proyecto de enseñanza desde la diferencia, pues la enseñanza se sigue concibiendo desde el foco en la figura de un docente que se espera sea respetado per se. 
Respecto a la tarea que el profesorado debe desarrollar, la complejidad es evidente y pone de manifiesto la presencia de un oficio que no es solo técnico, que tiene mucho de artesano. En correspondencia con la teoría, la labor del grupo docente es determinante en la generación de condiciones y en el diseño e implementación de estrategias que potencien en el estudiantado sus posibilidades de aprendizaje. Es importante considerar que la figura docente habitualmente se plantea en los siguientes términos:

El único que reúne en una sola persona las condiciones, espacios temporales, la fundamentación pedagógica y disciplinar, las posibilidades mediáticas y, por supuesto, lo que resulta más importante: la intención pedagógica de propiciar en una espiral formativa los aprendizajes de los alumnos. (Cuenca, Nucinkis y Zabal, 2007, p. 26)

Como parte de esta "todavía percepción parcial de la realidad de la docencia", el o la profesora en formación están necesitados de tiempo, reflexión y experiencia que les permita entender que la incertidumbre, la ignorancia y la complejidad no son obstáculos a despejar, sino elementos constitutivos de la práctica educativa que es preciso revisitar para lograr finalmente una adecuada inserción en el espacio del aula.

Enfrentado a este proceso, es posible constatar que el profesorado en formación es poseedor de saberes previos desde los cuales enfrentan los requerimientos de la práctica. Por tal razón, cuando se enfrentan a los desafíos de la tarea docente han de esforzarse por alcanzar un cierto equilibrio personal, pues, finalmente, la realidad subjetiva debe sintonizar con la realidad objetiva socialmente construida. Esto implica reconocer que "la relación entre el individuo y el mundo social objetivo es como un acto de equilibrio continuo" (Berger y Luckmann, 2001, p. 170).

Aun cuando es posible afirmar que la infancia se transforma en un tema desconcertante para la actuación docente, sus proyectores conceptuales muestran aún limitaciones para asumir que este cambio en la infancia no es necesariamente una debilidad, sino una oportunidad para redefinir su rol. En consecuencia, sus representaciones y sesgos los mantienen anclados a la añoranza según la cual al estudiantado no era preciso "convencerlo", ni tampoco era exigencia el acoger sus rasgos culturales, pues sencillamente la diversidad e inclusión no formaban parte del territorio del aula.

Estos proyectores les permiten entender que el perfil del cuerpo estudiantil que hoy habita las aulas se torna complejo por el influjo desbordante de las tecnologías de la información y por el rol y actitud que la familia muestra en el proceso. Sin embargo, no logran advertir el influjo que la misma escuela — como institución de la modernidad — tiene en la 
configuración de este nuevo escenario y en las dificultades para responder a las nuevas necesidades formativas del estudiantado. Es decir, enfrentados a la complejidad de la tarea docente, logran comprender las demandas planteadas por los actores involucrados. No obstante, siguen pensando en dar respuesta a aquello, volviendo a lo tradicional, a lo que justamente está siendo cuestionado y a lo que en definitiva, ha demostrado incapacidad de respuesta, pues se construye desde una racionalidad que niega la diversidad, pues como lo señala la teoría están basados en un modelo de educación homogénea, cuando hoy la sociedad globalizada se caracteriza cada vez más por su heterogeneidad.

\section{Conclusiones}

En este acercamiento cualitativo a las representaciones que los docentes en formación inicial de pedagogía básica, con mención de la Universidad Católica del Maule, desarrollan de los actores del aula y la naturaleza del trabajo docente en el espacio real de las escuelas, el estudio abre perspectivas de diálogo en el contexto regional, susceptibles de enriquecer la formación inicial e inserción docente en la medida que pueda superar la disyuntiva planteada por el paradigma de la modernidad en que estamos atrapados y que nos impide identificar los problemas reales: comprender y analizar situaciones complejas desde lógicas lineales, de relación causa- efecto, de fragmentación y análisis por partes.

Desde un punto de vista estratégico/operativo, si seguimos anclados al mismo modelo tecnológico, incluyendo sus expresiones actuales, lo único que podemos esperar, en línea con los principios tradicionales de la burocracia, será el privilegiar la racionalidad instrumental (medio/fin), la optimización de los recursos, la eficiencia en el uso de estos y la estandarización de objetivos y de procedimientos, con la correspondiente medición de resultados. En consecuencia, una cultura de la obediencia que difícilmente responde al nuevo territorio educativo, donde necesitamos avanzar en la concreción de una cultura de la curisiodad intelectual y del diálogo constructivo, con la puesta en práctica de lógicas "indefinidas e interactivas, confiando en una especie de improvisación normalizada, con una actividad que se fundamenta en consideraciones culturales, ético/morales y políticas" (Tenti, 2007, p. 346).

A manera de cierre, es preciso señalar que, a medida que se fue desarrollando la investigación, se puso de manifiesto el influjo de los propios sesgos en este proceso de representación de los actores y el trabajo docente. De ahí que resulta recomendable trabajar en torno a los sesgos de interpretación instalados en el cuerpo docente en formación, pues 
este permea fuertemente la lectura que hacen de la tarea docente y los significados que le atribuyen, lo que puede dar espacio a errores o sesgos de carácter perceptivos de mayor o menos impacto sobre la realidad que se interpreta.

En este sentido, el grupo docente en formación mira con añoranza cómo el aula y sus actores han cambiado, y de esa manera generan presión en los supuestos paradigmáticos que tienen de la docencia. Ello es clave al reconocer que estos docentes con proyectores conceptuales aun incompletos se enfrentan a los requerimientos de la docencia, interpretando, prediciendo y tomando decisiones, sustentadas en sus propias creencias, valores, intereses y preocupaciones. Es decir, las lecturas que realizan de los actores y del trabajo docente se relacionan con su forma de ver el mundo, según su mapa, sus creencias y respectivos filtros, sin ser necesariamente conscientes de las implicancias que ello tiene en la comprensión que logran de la tarea docente.

\section{Referencias}

Alfaro, Teresa. (2011). Desafío docente: el alumno postmoderno. Revista Digital de Investigación en Docencia Universitaria, 5(1), 1-12. Recuperado de http://revistas.upc.edu.pe/index.php/docencia/article/view/4/152

Berger, Peter y Luckmann, Thomas. (2001). La construcción social de la realidad. Buenos Aires: Amorrortu.

Berteaux, Daniel. (2005). Los relatos de vida. Perspectiva etnosociológica. Barcelona: Ediciones Ballaterra.

Biddle, Bruce, Good, Thomas y Goodson, Ivor. (2000). La enseñanza y los profesores I La profesión de enseñar. Barcelona: Paidós.

Carbonneau, Michel y Hétu, Jean-Claude. (2010). La formación práctica de los maestros y el nacimiento de una inteligencia profesional. En Léopold Paguay (Coord.), La formación profesional del maestro. Estrategias y competencias (pp. 107-138). México: Fondo de Cultura Económica

Cuenca, Ricardo, Nucinkis, Nicole y Zavala, Virginia. (2007). Nuevos maestros para América Latina. Madrid: Morata.

Day, Christopher. (2006). Pasión por enseñar. La identidad personal y profesional del docente y sus valores. Madrid: Narcea.

Edwards, Ernesto y Pintus, Alicia. (2001). Poder y seducción en la escuela. Rosario: Homo Sapiens.

Glaser, Barney y Strauss, Anselm. (1967). The Discovery of grounded theory. New York: Aldine publishing Compañy. 
Giroux, Henry. (1996). Educación posmoderna y generación juvenil. Nueva Sociedad, (146), 1-21. Recuperado de http://nuso.org/articulo/educacion-posmoderna-y-generacionjuvenil/

Hargreaves, Andy. (1994). Profesorado, cultura y postmodernidad. Madrid: Morata

Liston, Daniel y Zeichner, Kenneth. (1997). Formación del profesorado y condiciones sociales de la escolarización. Madrid: Morata.

Machado, Ana. (2015). Calidad y diversidad en la educación chilena. Recuperado de http://www.educarchile.cl/ech/pro/app/detalle?ID=91530

Pérez, Ángel. (2004). La Cultura Escolar en la Sociedad Neoliberal. Madrid: Ediciones Morata.

Pérez, Ángel, Martínez, Miguel, Tey, Amelia, Essombra, Miguel y González, María. (2007). Profesorado y otros profesionales de la educación. Madrid: Octaedro.

Schön, Donald. (1987). La formación de profesionales reflexivos. Barcelona: Paidós - MEC.

Schön, Donald. (1998). El profesional reflexivo. Cómo piensan los profesores cuando actúan. Barcelona: Paidós.

Schön, Donald. (2010). La formación de profesionales reflexivos: Hacia un nuevo diseño de la enseñanza y el aprendizaje en las profesiones. México: Paidós.

Tardif, Maurice. (2004). Los saberes del docente y su desarrollo profesional. Madrid: Narcea.

Tedesco, Juan y Tenti, Emilio. (2002). Nuevos tiempos y nuevos docente. Buenos Aires: IIPE - UNESCO.

Tenti, Emilio. (2007). Consideraciones sociológicas sobre profesionalización docente. Educação \& Sociedade, 28(99), 335-353. Recuperado de http://www.scielo.br/pdf/es/v28n99/a03v2899.pdf

Unesco. (2008). La educación encierra un tesoro. Madrid: Santillana.

Yániz, Concepción y Villardon, Lourdes. (2006). Planificar desde competencias para promover el aprendizaje. Bilbao: Universidad de Deusto. 